\title{
The Education Sector Revolution: The Automation of Education
}

\section{Mr. Hatem M Wasfy, Advanced Science and Automation Corp.}

Mr. Hatem Wasfy is the president of Advanced Science and Automation Corp. (ASA) a company that specializes in the development of online virtual learning environments, and advanced engineering simulations. He has helped design several interactive learning environments that include a CNC machining course, a centrifugal pump maintenance course, an undergraduate physics course, and a welding course. He received a B.S. in 1994 and an M.S. in 1996 in Mechanical Engineering from the American University in Cairo. Mr. Wasfy's research interests include advanced learning systems, cavitation modeling, computational fluid dynamics, internal combustion engine modeling and design, and AI rule-based expert systems.

\section{Dr. Tamer M. Wasfy, Indiana University Purdue University, Indianapolis}

Dr. Tamer Wasfy is an associate professor of Mechanical Engineering, at Indiana University-Purdue University in Indianapolis and chairman of Advanced Science and Automation Corp. (ASA). Prior to that, Dr. Wasfy worked as a research scientist at the University of Virginia at NASA Langley Research Center. Dr. Wasfy founded ASA in 1998. He is the software architect for commercial multibody dynamics, finite element and virtual-reality software systems that are marked by ASA and used by automotive and aerospace companies, government agencies, and academic institutions. Dr. Wasfy authored and coauthored over 75 peer-reviewed publications in the areas of flexible multibody dynamics, finite element modeling of solids and fluids, belt-drive dynamics, tires mechanics/dynamics, visualization of numerical simulation results, engineering applications of virtual-reality, and artificial intelligence. He received two ASME best conference paper awards as first author. Dr. Wasfy is a member of ASME, AIAA, SAE and ASEE. Dr. Wasfy received his Ph.D. in Mechanical Engineering from Columbia University in 1994.

\section{Prof. Riham M Mahfouz, Thomas Nelson Community College}

Riham Mahfouz has more than nine years of experience in teaching at the college level. She is currently working as the department head of the Chemistry department at the Thomas Nelson Community College (TNCC) where she teaches and serves as course coordinator for the following courses: preparatory chemistry, organic chemistry, and online college chemistry. Mahfouz has extensive training and experience in developing online courses. She has developed online college chemistry courses using the ASSURE Model of instructional design and the standards created by the Quality Matters faculty-centered peer review process for certifying the quality of online courses.

\section{Ms. Jeanne Peters, Advanced Science and Automation Corp.}

Jeanne Peters is the vice president of Advanced Science and Automation Corp. Peters received a B.A. in Math/Computer Science from the College of William and Mary. She worked at NASA Langley Research Center in Hampton, Va. for over 20 years as a senior programmer/analyst for George Washington University, University of Virginia, and Old Dominion University. She co-authored over 70 journal and conference papers in the areas of: computational mechanics, finite element method, shells/plates, composite material panels, and tires. She has also worked on numerous projects to create advanced engineering design and learning environments for space systems which include multimodal user interfaces. Peters directs the development of advanced virtual reality applications, including scientific visualization applications and web-based multimedia education/training applications at Advanced Science and Automation Corp. 


\title{
The Education Sector Revolution: The Automation of Education
}

\begin{abstract}
The education sector is about to undergo a revolution in which automation of instruction delivery using Intelligent Tutoring Systems (ITSs) will vastly improve accessibility to learning at a fraction of what that education costs today. This will be achieved while obtaining better student outcomes, and a more individualized learning experience as compared to traditional learning using human teachers in classroom settings. In this paper, we will present a review of the current state of ITSs along with the characteristics of a new more innovative ITS. The potential and consequences of this new learning paradigm will also be explored.
\end{abstract}

\section{Automation and Revolutions}

During the past 200 years a number of revolutions have taken place in the three main sectors of the world economy: the agricultural, industrial, and service sectors. The main traits of these revolutions have been a push towards automation that has caused a quantum leap in productivity, and a corresponding vast reduction in the need for human labor. The agricultural revolution for example resulted in an increase in cereal equivalent production from 1,000 kg per worker per year to $500,000 \mathrm{~kg}$ per worker per year using motorized and input intensive farming ${ }^{1}$. The industrial revolution started with the introduction of the steam engine and is ongoing today with advances such as automated factories and industrial robots. Several sub-sectors of the service sector are also undergoing their own revolutions ${ }^{2}$. For example the financial sector's use of money counting machines, Automated Teller Machines (ATMs) and internet banking are all aspects of the automation revolution that this sub-sector is undergoing.

Most sectors of the economy are moving at various rates towards more automation with the goal of reducing costs and increasing efficiency, quality, and reliability. Revolutions generally happen in 3 stages; the stage before the revolution, the stage during the revolution and the stage after the revolution. The stages can be discerned by plotting the employment data as the percentage of total workers employed in a given sector versus time (Figure 1). In the pre revolution stage, the percent of workers employed in the sector under investigation is stable and the curve is flat. During the revolution, the employment curve slopes downwards, as fewer workers are needed to perform the same functions. Finally post revolution, after the new technology matures in terms of development and implementation, the downwards slope of the percentage of workers employed in the sector decreases as new advances in automation technology bring evolutionary rather than revolutionary improvements in productivity. Looking at the percentage of the United States workforce that is employed in the agricultural sector (Figure 1), we can see that the agricultural revolution entered its post revolution stage in the US around the 1980s. The data for the manufacturing sector shows a downwards trend in the percentage of workers employed in this sector that starts around the 1960s. This is due to a number of causes including higher automation, a shift towards a service economy, and outsourcing of manufacturing jobs out of the US. The employment data for school and higher education teachers, on the other hand, shows a flat curve around $3 \%$ of the total workforce as would be expected in the pre revolution stage. 


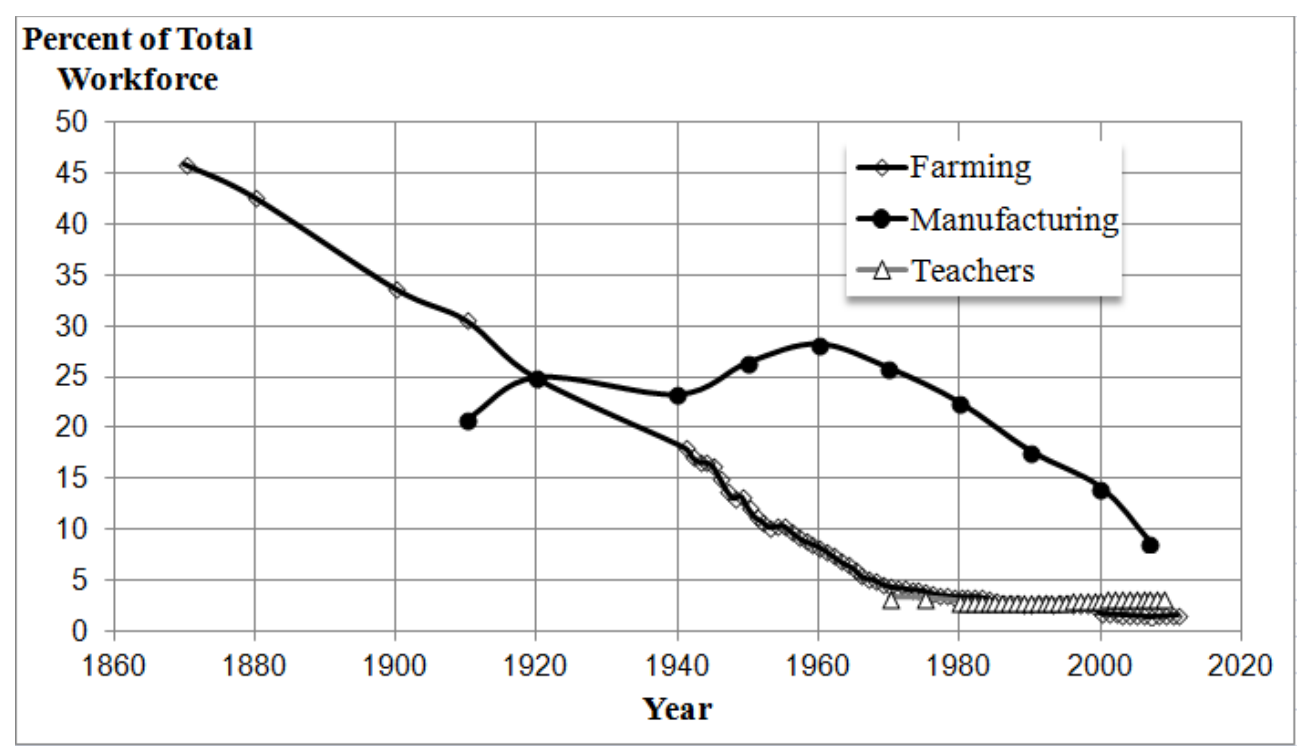

Figure 1. United States employment data ${ }^{3-6}$.

There are three main requirements for automation in any field to be viable: the availability of a technological solution that can replace human labor, the need for a large number of similar items, and a lower cost for automation as compared to manual methods at a similar or superior quality. Today, computer based Intelligent Tutoring Systems (ITSs) provide the required technological solution for instruction delivery automation at a fraction of the cost of traditional education. With more than 70 million students enrolled in primary, secondary and higher education in the US in $2010^{5}$, and many times that number worldwide, the cost of developing and delivering high quality ITSs can be spread out over a very large population of education services customers.

\section{Existing Automated Online Learning Systems}

Online courses where $80 \%$ or more of the content is delivered over the internet ${ }^{7}$ can be classified in terms of the degree of automation, which is inversely proportional to the degree of involvement of a human teacher in the education process ${ }^{8}$. Instructor delivered online courses are 0 to $29 \%$ automated, and are similar to a traditional course except for the fact that most of the instructor's activities including lecturing, answering questions and giving assignments and exams happen over the internet instead of face to face in a classroom ${ }^{8}$. Partially automated online courses have 30 to $79 \%$ of their content automated, while fully automated courses with more than $80 \%$ automation can be delivered with little or no involvement from a human teacher ${ }^{8}$.

Fully automated online courses currently fall into two main categories: Massive Open Online Courses (MOOCs); such as EdX ${ }^{9}$, coursera ${ }^{10}$, and Udacity ${ }^{11}$, and Intelligent Tutoring Systems (ITSs); such as ALEKS ${ }^{12}$, Carnegie Leaning's Cognitive Tutor ${ }^{13}$, AutoTutor ${ }^{14}$, and ANDES ${ }^{15}$. Table 1 provides a contrast between the characteristics of MOOCs and ITSs. MOOCs provide a venue for course designers to seamlessly develop and publish their courses. In ITSs, on the other hand, course development and course publishing are decoupled. Some ITSs have tools to facilitate the authoring of course content, but the publishing of these courses is usually handled by separate Learning Management Systems (LMSs). MOOC websites provide course credit for their enrolled students. ITSs, since they are customarily used as learning aids for an online or 
traditional course, simply report student performance to their LMSs but do not generally provide course credit.

Table 1. Comparison between the characteristics of MOOCs and ITSs.

\begin{tabular}{|l|l|}
\hline \multicolumn{1}{|c|}{ MOOCs } & \multicolumn{1}{c|}{ ITSs } \\
\hline Seamless course development \& publishing & Course publishing done externally \\
\hline Integrated course credit & Course credit granted externally \\
\hline Summative assessment & Formative assessment \\
\hline Linear course navigation & ITS course navigation \\
\hline
\end{tabular}

The assessments in most MOOCs are summative in nature, meaning they occur at the end of the learning activity and have no effect on the learning activity. ITSs use formative assessments, where the assessment is woven into the fabric of the course and student performance in the assessment activities affect how and when content is delivered. For example the ITS can skip a section, go over a section again, or go over more solved examples, all based on the result of the formative assessments. Summative assessment is sometimes called "assessment of learning", while formative assessment is called "assessment for learning." ${ }^{16}$ Studies in computer ${ }^{16}$, and classroom $^{17}$ based learning have shown that formative assessment improves student achievement.

Course navigation in MOOCs is typically linear, which means that a student is simply taken from one course section to the next one in a linear fashion that starts with the first course topic and ends with the last one. Hence with MOOCs, every student that takes the course experiences the course similarly. Every ITS on the other hand uses its own unique intelligent tutoring approach for course navigation that bases its course navigation decisions mainly on the results of the course's formative assessments. Hence in ITS delivered courses, each student might experience the course differently depending on their assessment results.

\section{The Future of ITSs}

An easy way of improving online automated courses is by combining the capabilities of MOOCs and ITSs. Hence MOOCs enhanced with ITSs can provide seamless course development, publishing, and credit granting; while using formative assessment and ITS based non-linear course navigation. There are also a number of innovations that can be used to further improve future ITSs:

\section{1) Integrated Virtual Reality}

Interactive Virtual Reality (VR) visualization and simulation capabilities are sometimes referred to as the "gamification" of learning ${ }^{18}$. VR based learning can be classified in terms of the hardware used into PC based systems and systems that use specialized hardware including custom setups that mimic real world setups, haptic devices, and stereo projection. VR learning systems can also be classified based on the number of learners that participate in the simulation into single user systems, and multiple user systems where multiple users collaborate in the context of a single VR simulation (Figure 2). Table 2 gives some examples of applications where the various categories of VR based learning have been used. Currently, the systems that use 
specialized hardware are too expensive to be implemented on a large scale for the general population of learners. As PCs become more powerful, with advanced displays that can handle stereo projection, and with the development of cheap general purpose haptic devices, it will become practical to run some of the VR simulations that currently require specialized hardware on inexpensive PCs.

Table 2. Examples of applications of the various categories of VR based learning.

\begin{tabular}{|c|c|c|}
\hline & Specialized hardware & PC based \\
\hline Multiple users & $\begin{array}{l}\text { - Flight simulators } \\
\text { - Ship operation }{ }^{19} \\
\text { - } \text { Defense }^{20}\end{array}$ & $\begin{array}{l}\text { - } \text { Defense \& law enforcement } \\
\text { - } \text { Medical }^{25,26} \\
\text { - } \text { Facility operation }^{26,28}\end{array}$ \\
\hline Single user & $\begin{array}{l}\text { - } \text { Welding }^{21-23} \\
\text { - } \text { Medical }^{24} \\
\text { - } \text { Defense }^{20}\end{array}$ & $\begin{array}{l}\text { - Manufacturing } \\
\text { - Maintenance } \\
\text { - Science labs } \\
\text { - }{ }^{32,33}\end{array}$ \\
\hline
\end{tabular}
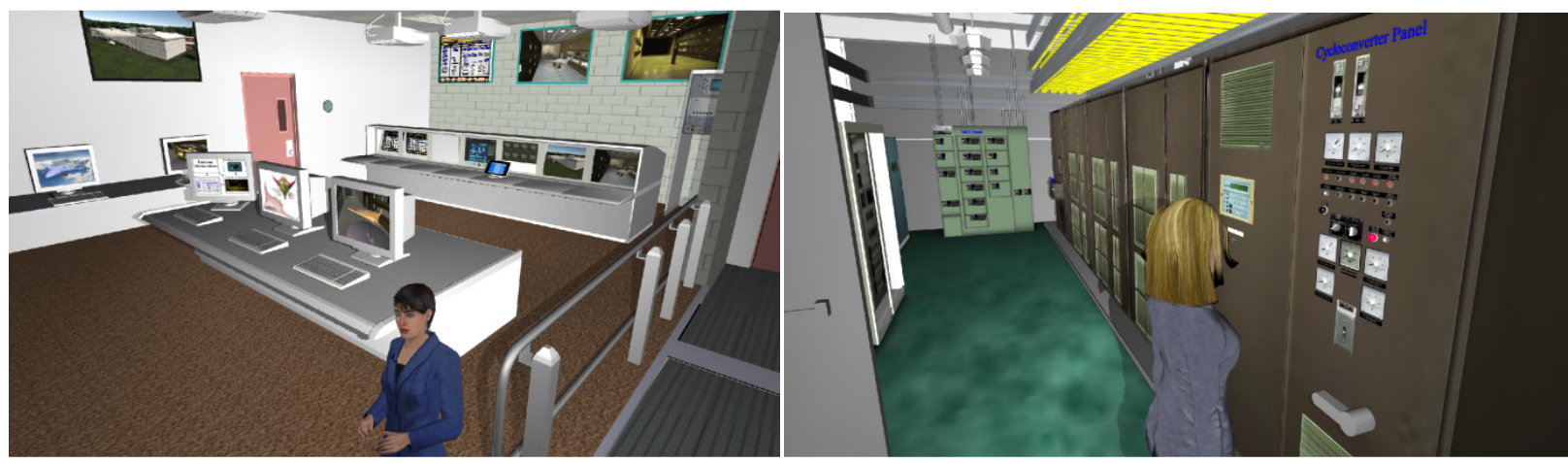

Figure 2. Multi-user PC based VR training environment for the operation of a wind tunnel showing the control room (left) and the electronics room (right) ${ }^{28}$.
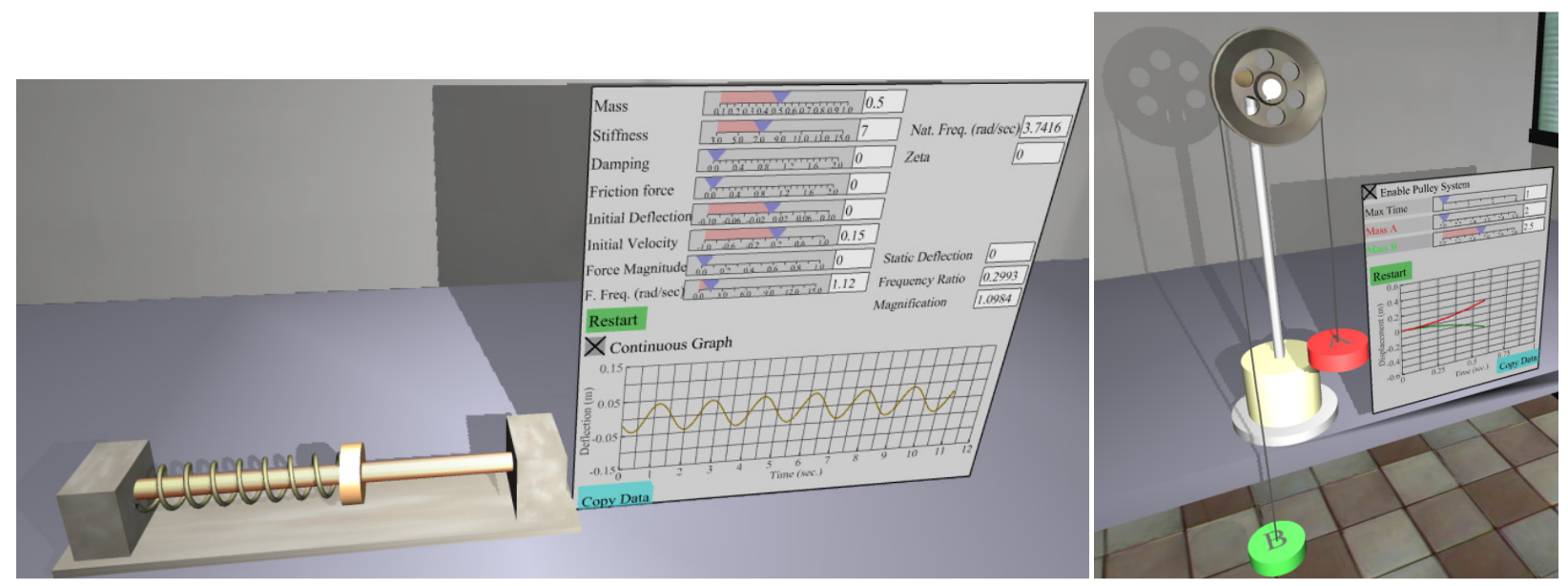

Figure 3. Physics based simulation of experiments in a virtual physics lab showing a horizontal mass-spring system (left), and a two mass rope-pulley system (right) ${ }^{33}$.

PC based systems can use custom made VR engines, or gaming VR engines. Although VR capabilities can be used in conjunction with some of the ITSs such as AutoTutor and MOOCs such as EdX, integrating these capabilities requires a lot of development work and specialized 
knowledge. Gaming VR engines, such the one used by one group to simulate gear trains ${ }^{34}$, generally lack accurate physics modeling engines. This is due to the fact that they usually make simplifying assumptions in order to reduce the computational cost of complex simulations. Those simplifying assumptions may cause violation of contact or joint constraints, and violation of conservation of energy and/or momentum principles. For game players those violations may not be perceptible ${ }^{35}$, but for engineering and science students those violations can result in students learning incorrect concepts. Some gaming ${ }^{36}$ and custom ${ }^{33,37}$ VR engines use first principle physics to model physical interactions and are thus more suitable for the simulation of dynamic effects in virtual science labs (Figure 3). Incorporating logic and complex simulations into a VR environment can require the use of a custom VR engine since a gaming engine might not be equipped to handle these requirements (Figure 4).

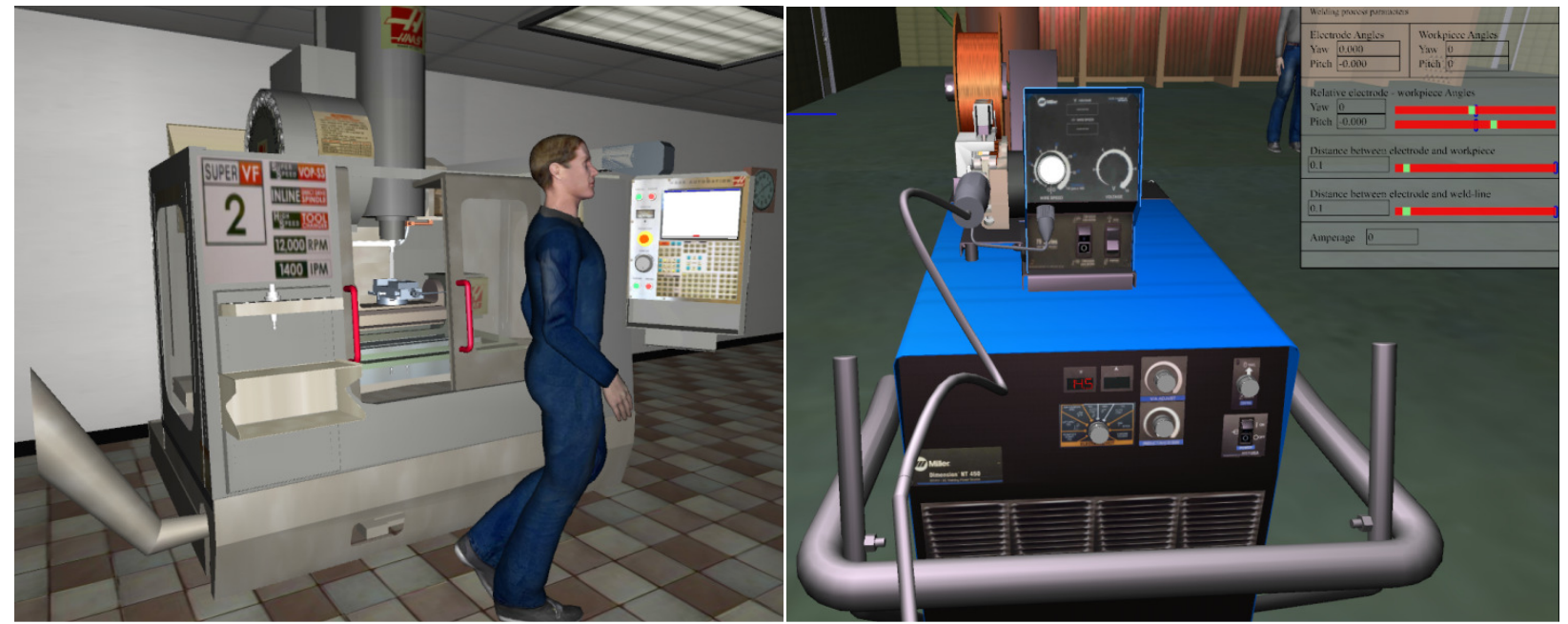

Figure 4. VR simulations performed using a custom VR engine. Simulation of a 5-axis milling machine that includes a fully functional controller to operate the virtual machine (left).

Simulation of the controls of a welding machine (right).

\section{2) Combining Courses into Curriculums}

Some ITSs organize a course into a set of interconnected ontology nodes, where each node represents a given course topic. Each node is made from one or more knowledge objects ${ }^{38,39}$ (KOs) or Sharable Content Objects ${ }^{40}$ (SCOs). KOs and SCOs are defined as "The lowest level of granularity of a learning resource" 40 (Figure 5). Each course node can be followed by a formative assessment to gauge student understanding in a process called Intelligent Formative Assessment $^{41}$ (IFA). Nodes that contain knowledge that is needed to understand the content in a given node are upstream of that node on the ontology tree. The ontology tree is used by the ITS to determine which node the student needs to see next, and to determine which node that is upstream of the current node needs to be reviewed in case of an assessment failure of the current node that cannot be remedied by viewing the current node again ${ }^{41}$. The ontology tree can also be used to combine different courses into curriculums by integrating their ontologies. This allows an ITS to deliver an entire curriculum seamlessly. This can also allow the ITS's remedial actions to cross course boundaries. For example, a failure in a Chemistry ontology node could trigger a reassessment of a related Algebra ontology node. Finally this will allow the ITS to ensure that the student has learned all the pre-required topics, even those from other course, before going 
over a curriculum node. For example before the delivery of an engineering curriculum topic about internal combustion engine dynamics, the system can take the student to prerequisite topics from courses in algebra and physics. In this case the curriculum is not delivered as successive courses; rather topics from different courses can be seamlessly woven together during curriculum delivery. This ensures the shortest time span between the time at which the student takes a given topic and the time at which he/she covers its prerequisite topic(s).

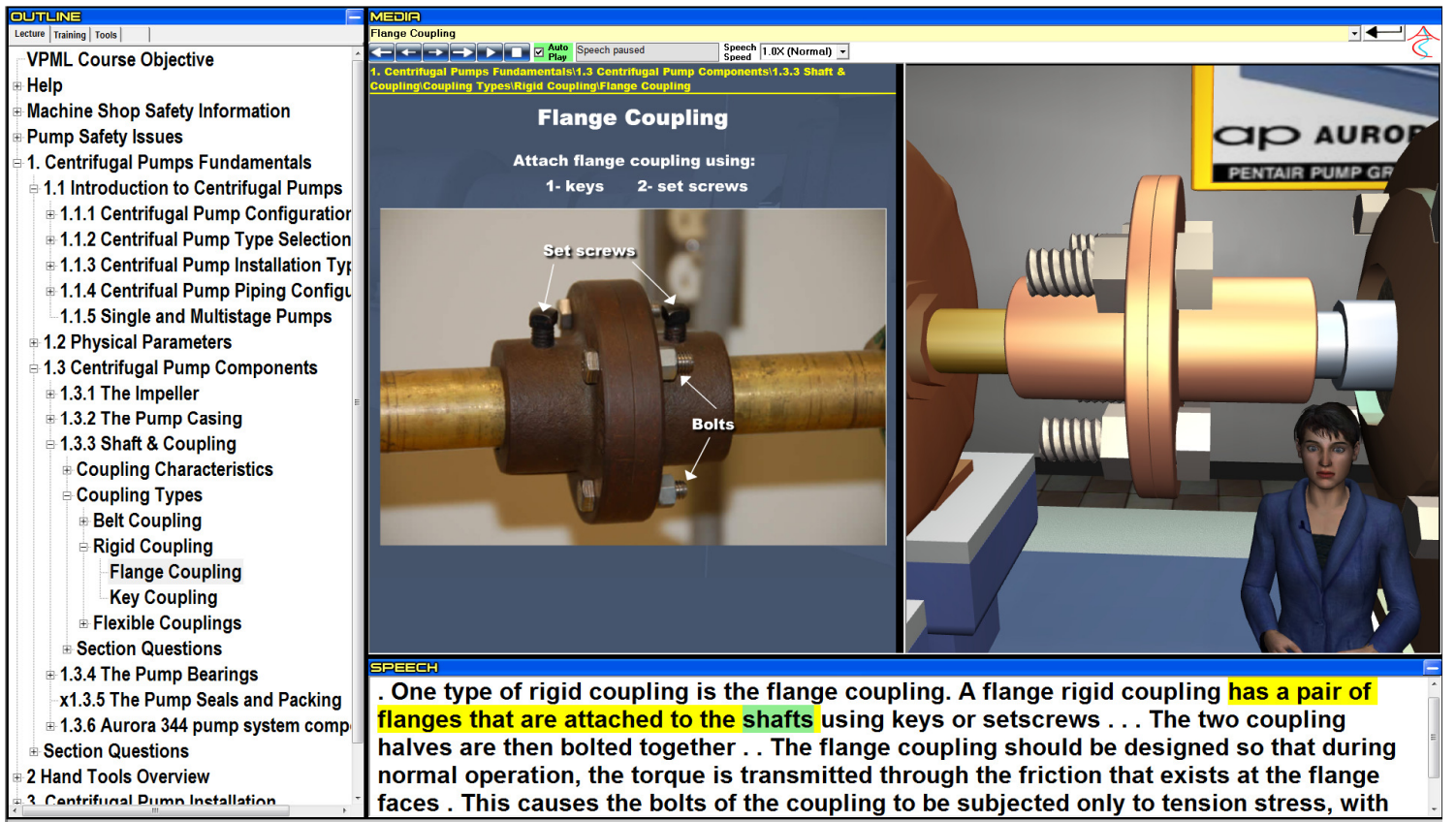

Figure 5. Knowledge object from an online centrifugal pump maintenance course. The hierarchical list on the left has the headings of other knowledge objects that constitute the course.

\section{3) Setting Learning Goals}

A common problem with traditional learning is that it tends to teach all students the same thing, in the same way, at the same pace, at the same sequence, at the same time ${ }^{42}$. This focus on mass produced uniform learning hinders learning when students are forced to learn in a way, at a pace, at a sequence, or in a time they are uncomfortable with. Mass produced uniform learning also produces a lot of inefficiencies since students often learn topics they are not interested in learning, or that they do not need based on their career goals, or that they already know but are forced to relearn anyway with the rest of the class.

The student's learning goals can range from learning an entire standard curriculum, to learning a single course, or even a single or multiple nodes from a single or several courses. In case the student chooses individual nodes from a given set of courses as his/her learning goals, the ITS automatically develops a custom curriculum for the student that takes him/her from his/her active nodes to his/her learning goals. The custom curriculum can span several courses while only covering the content from these courses that is needed to reach the student's learning goals. If the student chooses an entire course as part of his/her learning goals, the system automatically adds the prerequisite nodes that link the student's active nodes to the desired course. A standard curriculum by definition contains all the prerequisite nodes needed to reach its ultimate learning 
goals. In a traditional course, all students learn the same content. Thus traditional courses are not well suited for individualized delivery of custom courses that are designed to address diverse learning objectives and ultimate career goals. Students in traditional courses and curriculums invariably end up learning content that they never use nor need just because it is part of a given required course. Students can also be forced to take an entire class to satisfy a prerequisite condition, while all they need from that class might be a single chapter or even a part of a chapter. The customization of the learning experience that is afforded by the learning goals will not only increase student focus, but it will also reduce the cost and time of learning by eliminating topics that are not related to the student's learning objectives. The custom course or curriculum can be updated at any time in response to changes in the student's learning objectives as the student's goals and interests evolve. The ability of students to set their own education goals provides a means of individualized learning. Individualized learning was identified as a key to innovation in distance education by a group of experts in online learning ${ }^{43}$.

\section{4) Long Term Knowledge Retention}

In a study of a business consumer behavior course ${ }^{44}$ that involved repeated tests, it was found that most of the knowledge that students gained in the course was lost within 2 years. It is thus essential to find ways of improving student knowledge retention, since it is almost fruitless to improve learning outcomes, only to have students forget most of what they have learned within 2 years.

The expiration time of a given course node is used to calculate an expiration date for each node that the student learns by adding it to the node's successful assessment date. The successful assessment date is the later date of either the date on which the student successfully completes that node's assessment, or the date that the student successfully completes an assessment in a downstream node that also tests the comprehension of that given node. Since most courses and curriculums base their subsequent content on the comprehension of previous content, the assessment of subsequent or downstream content will also incorporate an assessment of previous or upstream content. For example, since the concept of "force" is a recurring one in any physics or engineering curriculum, the student will continue to be assessed in that concept as he/she is assessed in other related concepts while going through the curriculum. When a node's expiration date is reached, the intelligence engine automatically reassesses the node to ensure that the student still retains its knowledge. The course designer can edit the node's expiration time value and assign an expiration time other than the 2 years default based on the node's difficulty and criticality. This can ensure that students retain the knowledge they have learned for the long term as long as they keep using the ITS website to be reassessed in the content of their nodes as they expire. Since node reassessment can typically be done by answering one or a few short assessment questions related to the node, this should not place too much burden on the students while they are going through the curriculum.

The memory multiplier number is used to gauge how well a student retains knowledge. A value of 1 indicates average knowledge retention, a value of less than 1 indicates lesser than average and a value greater than 1 indicates higher than average knowledge retention. Every student is initially assigned a memory multiplier number of 1 . The memory multiplier number is increased when a student is successful in his/her reassessment of a topic whose expiration date has been 
reached, and is decreased in the case of a reassessment failure of the same. The memory multiplier number can range from 0.5 to 3 . Hence a student with higher than average memory retention capabilities will gradually see his/her memory multiplier number increased during his/her usage of the ITS website, while a student with less than average memory retention capabilities will experience a gradual decrease of his/her memory multiplier number. The memory multiplier number is multiplied by each node's expiration time to determine a new expiration date according to the following formula:

\section{Expiration Date $=$ Date of Assessment + Expiration Time $\times$ Memory Multiplier}

This allows the active nodes of students with good memory retention capabilities to expire at a slower rate than the active nodes of students with less than average memory retention capabilities. Although some ITSs such as ALEKS ${ }^{12}$ periodically reassess students to ensure that already learned topics are retained, this reassessment is performed within the context of the delivery of the course and not as a tool for retaining knowledge for years after going over the course. Furthermore, the student memory capabilities do not affect the frequency of reassessment. The continuous process of reassessing nodes as they expire ensures that the learned skills that the system reports for each student are accurate not only at the point in time when those skills are learned, but also perpetually after that point in time.

\section{The Student Model}

The ITS stores a student model for every student on the MOOC website. The student model stores the following information:

1. The student's identifying information.

2. The courses that the student is registered in. This includes the courses that the student is taking on his/her own, and the courses that the student is taking under the supervision of a teacher, professor, or employer. If the student is taking a course under supervision, then his/her identity and student model for that course is available for viewing by his/her course supervisor.

3. Active nodes. Any node within any course on the website that the student has successfully been assessed in and whose expiration date has not been reached yet is regarded as an active node.

4. Expired nodes. These are the nodes whose expiration dates have passed that the student has not yet been reassessed in. The system prompts the student periodically to take an assessment of the knowledge in these nodes to turn them back into active nodes.

5. Dropped nodes. These are nodes whose expiration dates have passed that the student has chosen not to be reassessed in.

6. The student's learning goals.

7. The student's memory multiplier number.

8. Terminal failure nodes. A terminal failure in a given node is defined as an assessment failure that cannot be remediated by going over the knowledge in the node again or in more detail, and that is not related to a lack of understanding of an upstream node ${ }^{41}$. The ITS then directs the student to other course nodes that are not downstream of the terminally failed node. The course designer is periodically alerted of the number of terminal and regular failures in each 
course node. This information is used to help improve the course by identifying problematic nodes that students are having difficulties with. The course designer can then redesign these nodes or add more explanation to them to improve student comprehension of their topics. In the case where the student is taking the course under the supervision of a teacher or professor, the course supervisor can communicate directly with the student who has experienced a terminal failure to offer one-on-one help.

As compared to the student transcript, the student model provides a much more effective way of tracking and sharing the student's current proficiencies (Table 3). While the transcript lists the courses that the student has taken, the student model provides much more details by listing a student's active, expired and dropped individual topics. The transcript reports the average student understanding for every listed course. Hence even a student who finishes a course with an A grade might actually have a failing proficiency level in one or more critical course topics. This in turn creates negative repercussions on the students' job performance, and in downstream courses due to students not fully grasping some of the prerequisite knowledge. The lack of information about the actual student proficiency in the critical skills that he/she needs to perform their job sometimes necessitates a retraining of all personnel in these skills at a high cost for employers. The student model, on the other hand, reports the current actual student understanding of each listed topic. Furthermore, in order for a topic to be listed as active in the student model, the student must have achieved and maintained the required level of proficiency in that topic.

Table 3. Comparison between the student model and the student transcript.

\begin{tabular}{|l|l|}
\hline \multicolumn{1}{|c|}{ Transcript } & \multicolumn{1}{c|}{ Student model } \\
\hline Lists the courses that student has taken & Lists student's active, expired, and dropped topics \\
\hline $\begin{array}{l}\text { Reports courses' average student } \\
\text { understanding }\end{array}$ & Reports actual student understanding of each topic \\
\hline Smallest incremental addition = 1 course & Smallest incremental addition = 1 topic \\
\hline $\begin{array}{l}\text { Reports what student has studied at some } \\
\text { point }\end{array}$ & Reports what student knows now \\
\hline $\begin{array}{l}\text { Does not measure a student's memory } \\
\text { abilities }\end{array}$ & Provides a measure of student's memory abilities \\
\hline Updated periodically & Updated in real-time \\
\hline Costs money to produce and mail & Free to access and share with others \\
\hline Lists student's intended degree(s) & Lists student's intended educational goals \\
\hline Vague timeframe for degree completion & Individual and collective goals' timeframes \\
\hline
\end{tabular}

In the case of the transcript, the smallest incremental addition is equal to one course, while for the student model, the smallest incremental addition is equal to a single topic. This helps focus the student's efforts on what he/she needs to learn, and reduces wasted effort if all one really needs from a certain course to achieve a given learning goal is just a few topics. This can also help workers to respond more quickly to any new needs in their jobs that require them to acquire new proficiencies. Traditionally, a worker can satisfy these needs by taking a course in the needed field, but this usually takes an entire semester without counting the time that the worker might need to wait if the course is not available for registration right away. Using the student model, on the other hand, a worker can acquire the required new proficiencies by adding them as learning goals to his/her student model. The system then automatically develops a custom course 
that starts from the worker's active topics and covers only the topics that link the active topics to the new learning goals. This can allow workers to acquire the new proficiencies in days or weeks instead of months in the case of taking a traditional course.

A student's transcript contains information about what that student has studied at some point in the past, which might be very different from what the student actually knows or can remember now. Due to the fact that topics are reassessed when their expiration dates are reached, the student model, on the other hand, provides a much more accurate representation of what the student currently knows. An argument can be made that this periodic reassessment of learned topics can become burdensome specially when performed years after the student has finished the related curriculum while the student is employed. As mentioned before, the reassessments of a given node can be done using a single or a few questions that take a minute or less each to answer. Furthermore, each reassessment questions can test several nodes simultaneously by incorporating several concepts. Students are also not forced to take these reassessments and can simply let their nodes expire, or drop nodes whose knowledge they no longer need to be certified in. A similar periodic reassessment is often required of workers who perform critical functions although it is often not done in an automated manner. For example the knowledge of pilots about flight procedures is periodically reassessed in a flight simulator, and drills that are performed by various workers from cruise ship crews to nuclear reactor operators serve as reassessment to certify that workers still retain critically required knowledge. The question is why should other workers like engineers, doctors and pharmacists be held at a lower standard by not periodically reassessing their knowledge and certifying that they remain competent in the tasks that their jobs require? This continuous reassessment and certification will not only help workers remain competent, but can actually save lives and money by making sure that workers still remember the knowledge required to perform critical functions. For example, a civil engineer who has learned to design both buildings and bridges might work for years designing only buildings which might cause him to forget some of the knowledge he needs to design bridges over time. The employer of said engineer might then at some point require him to design a bridge after first having checked his transcript to ascertain that he has the required coursework. The problem is that the engineer himself might not be aware that he has lost a key competency that is related to bridge design which might result in a disaster. If the employer had checked the engineer's ITS generated student model instead, the status of the engineer's bridge design nodes would have been apparent, and had those nodes been expired or dropped disaster could have been averted.

While the transcript does not provide any information about a student's memory retention abilities, after a few years of using the ITS website, the student model can provide a measure of whether the student's knowledge retention is above or below average. Another advantage of the student model is that it is updated in real time as soon as the student finishes a given topic, while the transcript is only updated periodically, usually at the end of every semester. It can cost tens of dollars to produce and mail each student transcript, while a student model can be accessed at any time by the student or anyone designated by him/her for free. In terms of educational goals, the transcript usually lists the student's intended major(s), minor(s), and degree(s). The student model, on the other hand, provides a much more detailed picture of the student's educational goals by providing a list of the topics he/she ultimately wants to learn and all the topics he/she will need to learn to reach these goals. This can allow a worker's employer to focus his/her efforts on exactly what they need to learn to perform well in their intended position. Finally, by 
stating the student is for example in his second or Sophomore year, a transcript only supplies vague information about the timeframe for the student to complete his/her degree. The student model, on the other hand can provide a much more accurate time frame in terms of average required person-hours to complete each of the student's learning goals individually, as well as the average time needed to complete all the of student's chosen learning goals.

\section{Human Teacher vs. ITS}

By comparing a human teacher to the ITS (Table 4) we can more clearly see both the advantages and disadvantages of the ITS. In terms of the pre-requisite knowledge that the student needs to have before taking the course, the human teacher can only inform the student about what entire course(s) he/she needs to take before being ready to take the current course. The ITS, on the other hand, informs the student of the specific topics he/she needs to take to link his/her active nodes with the course's nodes. Those nodes can be ones that the student has never taken before, or ones that the student has previously been assessed successfully in but subsequently failed, dropped, or left in an expired state. The human teacher can check whether or not the student has taken the pre-requisite course and scored the required grade for passing on average in the entire course. The ITS, on the other hand, ensures that the student has the required level of proficiency in every pre-requisite topic and that he/she still retains that knowledge.

In terms of the individualization of learning experience, while a human teacher teaches a standard course to all students who are taking the course, the ITS teaches a custom course to each student based on his/her initial knowledge and learning goals. The Human teacher uses the same rate to teach the course to all students which might be too slow and boring for some and too fast and confusing to others. The ITS teaches every student at his/her optimal rate, and can even skip over sections of the course if it determines through a pre-assessment that the student already has the knowledge contained in those sections.

The goal of the human teacher is to ensure that every student reaches the required proficiency level on average in the content of the entire course. The ITS, on the other hand, can ensure that every student not only reaches, but also maintains the required proficiency level in every course topic. Furthermore, while the human teacher has a finite amount of time to devote to each student, the ITS can keep working indefinitely to teach and re-teach the course's knowledge to each student. Although some teachers are using computer based assignments, for a traditionally taught class manual grading of homework and exams is still the norm. Returning manually graded homework and exams takes days, and the grading and preparation of these assessments consumes a large portion of the teacher's effort. Assessments for an ITS taught course are administered automatically and evaluated instantly. For an ITS, the evaluation of these assessments is not for grading purposes, but rather to ensure that the student has reached the required level of proficiency in every topic and to determine and remedy failures. In an ITS administered course, the student does not receive a grade in the course as a whole or in any specific topic, rather the system certifies that the student has achieved and maintains the required

proficiency level, which could be equivalent to an A, in every course topic. This is called this the "no skill left behind" approach ${ }^{41}$. 
Table 4. Comparison between a human teacher and an ITS.

\begin{tabular}{|l|l|}
\hline \multicolumn{1}{|c|}{ Human } & \multicolumn{1}{c|}{ ITS } \\
\hline $\begin{array}{l}\text { Can inform the student of the pre-requisite } \\
\text { courses he/she needs to learn }\end{array}$ & $\begin{array}{l}\text { Can inform the student of the pre-requisite } \\
\text { topics that he/she needs to learn or re-learn }\end{array}$ \\
\hline $\begin{array}{l}\text { Checks that the student has taken the pre- } \\
\text { requisite courses and scored the required } \\
\text { grade for passing }\end{array}$ & $\begin{array}{l}\text { Ensures that the student has the required } \\
\text { proficiency level in the pre-requisite topics } \\
\text { and that he/she still retains that knowledge }\end{array}$ \\
\hline Teaches a standard course to all students & Teaches a custom course to each student \\
\hline Teaches at the same rate to all students & Teaches each student at his/her optimal rate \\
\hline $\begin{array}{l}\text { Seeks that every student reaches the required } \\
\text { proficiency level on average in the whole } \\
\text { course }\end{array}$ & $\begin{array}{l}\text { Ensures that every student reaches and } \\
\text { maintains the required proficiency level in } \\
\text { every course topic }\end{array}$ \\
\hline Homework and exams are returned in days & Assessments are evaluated instantly \\
\hline $\begin{array}{l}\text { Has a finite amount of time to devote to each } \\
\text { student }\end{array}$ & $\begin{array}{l}\text { Has an infinite amount of time to devote to } \\
\text { each student }\end{array}$ \\
\hline Several teachers teach a curriculum & $\begin{array}{l}\text { One system can teach an entire curriculum } \\
\text { seamlessly }\end{array}$ \\
\hline Time to complete course $=1$ semester & Student chooses time to complete course \\
\hline Requires steady progress rate & Can accommodate sporadic progress rate \\
\hline $\begin{array}{l}\text { Same course variability due to instructor's } \\
\text { skill and focus }\end{array}$ & No same course variability \\
\hline Costs $\$ 30$ to $\$ 100$ per hour & Costs $\$ 10$ to $\$ 50$ per course per student \\
\hline $\begin{array}{l}\text { Can understand and answer all natural } \\
\text { language questions }\end{array}$ & $\begin{array}{l}\text { Can understand and answer some natural } \\
\text { language questions }\end{array}$ \\
\hline $\begin{array}{l}\text { Good ability to adapt content delivery to } \\
\text { student needs }\end{array}$ & $\begin{array}{l}\text { Limited ability to adapt content delivery to } \\
\text { student needs }\end{array}$ \\
\hline Can ascertain student's identity & Cannot ascertain student's identity \\
\hline
\end{tabular}

In terms of the availability of the human teacher to his/her students, the human teacher is available only at specific times to student while they are taking his/her course. The ITS, on the other hand, is available to students any time, day or night, perpetually. Additionally, while several teachers, that can be from different institutions, teach an entire curriculum, the ITS can teach an entire curriculum seamlessly. The time required to complete a standard course that is taught by a human teacher is typically one semester. The time required to teach an ITS delivered course, on the other hand, can be anything the student chooses. This ITS feature is beneficial for those who want to further their knowledge while being busy with other things like work or family, which prevent them from being able to finish a typical course in a single semester. By taking an ITS delivered course over a period of a year or longer, those individuals would be able to finish the course without putting too much strain on their professional or personal lives. On a related note, traditional instructor delivered courses require that all the students taking the course progress at the same rate within the course. This allows students to be prepared for the successive parts of the course when they are taught, and for the homework and exam assessments when they are offered. In an ITS delivered course, on the other hand, since each student takes the course individually and not as part of a group, students can progress through the course at any rate they choose. Hence a student can finish a big chunk of the course when he/she is free, and 
can put the course aside for a few weeks or months if he/she becomes busy with other things. Additionally, even when the same course is being taught at the same school out of the same textbook, even sometimes by the same instructor, there still will be variability in the instruction that the students receive. This can be due to variability in the skill and focus of the instructor amongst other factors. For example, some instructors might skip entire sections of the course that they deem irrelevant, while others might include material from outside the course's textbook that might relate to their own research because they deem it important. For a course delivered via an ITS, on the other hand, there is no same course variability for different students taking the course. Finally, while a human teacher costs 30 to 100 dollars per hour, the ITS is expected to cost no more than 10 to 50 dollars per course per student.

Although, as we have seen above, the ITS has several advantages over human teachers, the ITSs that are achievable with current technology suffer from a few disadvantages as compared to humans. Human teachers can understand and answer all natural language questions that their students can pose. In order to give the ITS the ability to interpret natural language, either in speech or typed form, an expert system with a very large number of complex rules is required even for limited domains of knowledge ${ }^{45}$. The task of developing an expert system to interpret natural language questions about a vast knowledge domain, such as an entire physics or chemistry course is not impossible. Rather that task is impractical since it will involve the development of a huge amount of interconnected rules in an effort that can be several orders of magnitude greater than the effort required to prepare the knowledge domain's content. The human teacher is also able to adapt the way he/she presents the course to the needs of the student(s). However, this ability is somewhat limited in a classroom or lecture hall setting with tens or hundreds of students. The ITS, on the other hand, has a limited ability to adjust the way it presents content in response to the needs of individual students. This limitation however can be partially overcome by creating more complex interactions between the ITS and the student during assessments that include scaffolding and adjustments to the level of granularity of the interaction. Granularity refers to the amount of reasoning required of participants between opportunities to interact ${ }^{46}$. The coarsest granularity occurs in single answer questions, while a finer granularity can have multiple steps to reach the final answer with rules that govern the ITS's response for different answer scenarios. ITS delivered step-based assessments were found in one study to deliver better student outcomes than the single answer assessment approach, and almost equivalent student outcomes as compared to human tutoring ${ }^{46}$. Finally, while a human teacher can ascertain the identity of the student who is taking the course, the ITS currently possesses no such ability. However, the identity of students taking ITS administered courses can be ascertained, and their proficiency can be confirmed using a proctored summative exam that can be administered by the ITS at a designated testing station with human supervision.

\section{Effectiveness of ITSs}

In numerous studies up to 2001, it was shown that students who learn solely using high quality online resource achieve a similar proficiency level to students in traditional classroom settings ${ }^{47}$. Bloom $^{48}$ defined the effect size of an intervention as:

Effect Size $=\frac{\text { Average }_{\text {Study }}-\text { Average }_{\text {Conventional }}}{\sigma_{\text {Conventional }}}$ 
Where the Average $_{\text {Study }}$ is the average student score with the intervention, Average Conventional is the average student score in the traditional classroom setting, and $\sigma_{\text {Conventional }}$ is the standard deviation of the student scores in the traditional classroom setting. Bloom ${ }^{48}$ compared traditional classroom instruction outcomes with the outcome of one-on-one tutoring. Bloom found that the effect size of one-on-one tutoring was $+2 \sigma$. Some studies suggest ${ }^{49}$ that while the best computer based learning systems that do not have intelligence aspects produce an effect size around +0.4 $\sigma$, current Intelligent Tutoring Systems ${ }^{15,50}$ produce an effect size between +0.6 and $+1.2 \sigma$. A small study of a fully automated undergraduate machining course with linear content delivery (no ITS) suggests that in terms of student comprehension, using only a well designed fully automated online course is as effective as traditional classroom/textbook/lab instruction ${ }^{51}$. The effect size for future more advanced ITSs incorporating the above mentioned capabilities is expected to equal or even exceed the effect size of one-on-one tutoring.

Bloom's effect size however does not take into account the much smaller cost of ITS administered courses, nor does it take into account the fact that it requires on average less time from the student to go over an ITS course as compared to the total time required to travel to school, attend lectures, perform laboratory experiments, do homework assignments, go to office hours, study for exams, take exams, and other tasks that need to be performed as part of a traditional course. A more meaningful merit criterion was developed that takes these aspects into account $^{41}$, where:

Merit Criterion $=(1+$ Effect Size $) /($ Cost Ratio $\times$ Time Ratio $)$

Cost Ratio $=\frac{\text { Cost }_{\text {Study }}}{\text { Cost }_{\text {Conventional }}} \quad$ Time Ratio $=\frac{\text { Time }_{\text {Study }}}{\text { Time }_{\text {Conventional }}}$

While the merit criterion of the base case is one, interventions with a score that is larger than one are better overall in terms of cost, amount of time spent by the students and effectiveness than the base case. In a meta-analysis study of 32 computer-based courses, the time required to finish the computer based course was two thirds the time required to finish a similar conventional classroom course without taking commute time into consideration ${ }^{52}$. The cost ratio for an ITS, while taking conventional classroom learning as the basis, can be as low as 1/100 or less.

\section{Expected Effect of ITSs on Employment in the Education Sector}

Automation in the agricultural and industrial sectors has resulted in a huge reduction in the number of workers required to perform agricultural and industrial related jobs. Similarly, when instead of teaching tens of students, a single teacher can supervise hundreds of students who are learning from an ITS, an order of magnitude reduction in the number of teaching jobs will result. Just like the Luddites revolted against industrialization, there will be an expected resistance from teachers to this development. At the end, just like with all the previous revolutions that took place in other sectors, economics will trump everything. When students and governments will realize that the same education offered by conventional methods can be acquired using ITSs at $1 / 100$ of the cost of conventional methods, this will drive an explosive growth in ITS adaptation. Although kindergarten and primary education students will always require a more human 
intensive teaching, students in middle school, high school, and higher education will all benefit from the shift to ITSs.

What this will mean for teaching jobs at all education levels is that many of these jobs will permanently disappear. But just like the disappearance of farm hand jobs and the jobs of riveters on assembly lines this will not necessarily be a bad thing. For just like some of those manual labor jobs became engineering, science and indeed teaching jobs, those who would have become teachers in the old economy might become tomorrow's nanotechnologists, or space colonists. In this case the overall economy will win when people learn to race with rather than against automation $^{53}$. Educational institutions will also have to adapt to this new learning paradigm or otherwise face extinction just like factories that refused to adopt automation and farms that insisted on relying on manual labor.

According to a recent report by Moody's Investor Service ${ }^{54}$, the success or failure of the providers of new open online courses will be dictated by "the breadth and nature of the careeroriented offerings, ultimate cost to students, type of academic credit received, and value of that academic credit to potential employers." The British educationalist Sybil Marshall is reported to have said: "Education must have an end in view, for it is not an end in itself." M5 Most students take courses not simply to gain interesting knowledge, but ultimately to receive credentials that are acceptable to potential employers. Hence one way for ITS delivered courses to gain traction, is by being offered by conventional institutions that will provide these credentials similarly to what they provide for conventionally taught courses. However, conventional institutions might be reluctant to take that step out of fear of losing revenues due to higher paying students in conventional classes shifting to low cost ITS delivered alternative courses. Alternatively ITS course providers that exist solely online could back up their course offerings with credentials, but those credentials might not be widely accepted if they are not endorsed by reputable conventional institutions.

\section{Conclusions}

ITSs can deliver not just a course, but an entire curriculum seamlessly, and can continuously assess student learning during course delivery to ensure that each student achieves full proficiency in every course topic. Furthermore, ITSs can pinpoint the root cause of any assessment failure of the student by tracking the cause of failure up through the ontology tree of the course. Finally, ITSs can ensure that students retain the knowledge that they have gained perpetually if they keep using the ITS system by assigning expiration dates to the learned knowledge that are a function of the knowledge's difficulty, and criticality, and on the measured memory ability of each student. The large number of students who are required to learn the same content in numerous topics provides an ideal setting for developing automated ITS delivered courses at a very small development cost per student. ITSs can also deliver courses and virtual reality labs at a small fraction of the cost of traditional learning methods without the need to pay for human instructors, textbooks, class/lab space, lab equipment, or consumables. Furthermore, since computer based ITS courses are delivered over the internet, campus housing and transportation costs for students can be eliminated. Finally, research has shown that well designed ITSs can be more effective than traditional classroom instruction, and we expect future ITSs will be more effective even than one-on-one tutoring. All this leads us to believe that ITSs 
will soon dominate the education field which will result in an inevitable large reduction in available teaching jobs. This development will help the overall world economy by opening up education opportunities for people worldwide that are currently too expensive to pursue.

\section{Bibliography}

1. Food and Agriculture Organization of the United Nations (FAO). The State of Food and Agriculture 2000. www.fao.org/docrep/x4400e/x4400e00.htm

2. Collier, David A. Service Management: The Automation of Services. Prentice Hall. 1985.

3. The United States Census Bureau. www.census.gov

4. Gibson, C. American Demographic History Chartbook: 1790 to 2000. 2010. www.demographic chartbook.com

5. National Center for Education Statistics. nces.ed.gov

6. United States Department of Labor: Bureau of Labor Statists. www.bls.gov

7. Allen, E., and Seaman, J. Going the Distance: Online Education in the United States, 2011. The Sloan Consortium, November 2011. See also URL http://sloanconsortium.org

8. Wasfy, H.M., Wasfy, T.M., Peters, J.M. and Mahfouz, R.M. "Online Automated Interactive Undergraduate Physics Course and Lab." The $119^{\text {th }}$ Annual American Society for Engineering Education Conference \& Exposition, San Antonio, TX, June 2012.

9. www.edx.org

10. www.coursera.org

11. www.udacity.com

12. www.aleks.com/about_aleks

13. Ritter, S. The Research Behind the Carnegie Learning Math Series. Carnegie Learning. www.carnegielearning.com/whitepapers/11

14. www.skoonline.org/home

15. VanLehn, K., Lynch, C., Schulze, K., Shapiro, J.A., Shelby, R., Taylor, L., Treacy, D., Einstein, A., and Wintersgill, M. "The Andes Physics Tutoring System: Lessons Learned." International Journal of Artificial Intelligence in Education, 15(3), pp. 147-204, 2005.

16. Shute, V.J., Hansen, E., and Almond, R. "You Can't Fatten a Hog by Weighing it - Or Can You? Evaluating an Assessment for Learning System Called ACED." International Journal of Artificial Intelligence in Education. 18(4), 2008.

17. Black, P., and Wiliam, D. "Assessment and classroom learning." Assessment in Education: Principles, Policy \& Practice. 5(1), pp. 7-71, 1998.

18. Benderly, B.L. "Bold Experiment: Universities Face New Competition as Elite Schools Offer Course Certificates to the Online Masses." Prism. 22-2, pp. 28-33, October 2012.

19. Safer, A. "A Picture is Worth a Thousand Words." Marine Log. 117-11, pp.48-49, November 2012.

20. www.peostri.army.mil

21. VRTEX Virtual Reality Arc Welding Trainer. www.lincolnelectric.com/en-us/equipment/trainingequipment/Pages/vrtex.aspx

22. www.123arc.com/en/

23. The Virtual Welding Trainer. www.vlearn.com/welding/index.php/en/

24. Forsslund, J., Sallna, E.-L., Palmerius, K.-J. "A user-centered designed FOSS implementation of bone surgery simulations," World Haptics Conference, pp. 391-392, World Haptics 2009 - Third Joint EuroHaptics conference and Symposium on Haptic Interfaces for Virtual Environment and Teleoperator Systems, 2009. www.csc.kth.se/ jofo02/Forsslund_Sallnas_Palmerius_2009_World_Haptics.pdf

25. www.jht.com/training_simulations.html

26. www.virtualheroes.com

27. www.wisdomtools.com

28. Wasfy, H.M., Wasfy, T.M., Peters, J.M. and El-Mounayri, H.A. "Automated Online Process Training in a Virtual Environment." The $119^{\text {th }}$ Annual American Society for Engineering Education Conference \& Exposition, San Antonio, TX, June 2012. 
29. Wasfy, T.M., Wasfy, A.M., El-Mounayri, H., and Aw, D., "Virtual training environment for a 3-axis CNC milling machine," ASME DETC2005-84689 (Best paper award 'Applications'), 25th Computers and Information in Engineering (CIE) Conference, Long Beach, CA, 2005.

30. El-Mounayri, H., Aw, D., Wasfy, T.M. and Wasfy, A.M., "Virtual CNC Machining: A Comprehensive Approach," 35th International Conference on Computers and Industrial Engineering (ICC\&IE), Turkey, June 2005.

31. El-Mounayri, H., Aw, D., Wasfy, T.M. and Wasfy, A.M., "A Virtual manufacturing laboratory for training and education," ASEE 2005 Annual Conference, Portland, OR, 2005.

32. Wasfy, H.M., Wasfy, T.M., Peters, J.M. and Mahfouz, R.M. "Online Automated Interactive Undergraduate Physics Course and Lab." The $119^{\text {th }}$ Annual American Society for Engineering Education Conference \& Exposition, San Antonio, TX, June 2012.

33. Wasfy, H.M., Wasfy, T.M., Peters, J.M. "Flexible Multibody Dynamics Explicit Solver for Real-Time Simulation of an Online Virtual Dynamics Lab." The $119^{\text {th }}$ Annual American Society for Engineering Education Conference \& Exposition, San Antonio, TX, June 2012.

34. Chang, Y., Aziz, E-S., Esche, S.K. and Chassapis. C. "A game-based laboratory for gear design." Computers in Education Journal, Vol. 3(1), pp. 21-31, 2012.

35. Yeh T.Y., Reinman G., Patel S.J. and Faloutsos P. "Fool me twice: Exploring and exploiting error tolerance in physics-based animation," Journal ACM Trans. Graph. (TOG), Vol. 29(1), 2009.

36. Real-Time Physics Effects Library (RPEL). www.virtualheroes.com/products/real-time-physics

37. Wasfy, T.M., Wasfy, H.M, and Peters, J.M., "Real-Time Explicit Flexible Multibody Dynamics Solver with Application to Virtual-Reality based E-learning", (2011). ASME DETC2011-48846, Proceedings of the ASME 2011 International Design Engineering Technical Conferences \& Computers and Information in Engineering Conference, Washington, DC, August 2011.

38. Wasfy, A.M., Wasfy, T.M., El-Mounayri, H., and Aw, D., "Web-based multimedia lecture delivery system with text-to-speech and virtual instructors," ASME DETC2005-84692, 25 ${ }^{\text {th }}$ Computers and Information in Engineering (CIE) Conference, Long Beach, CA, September 2005.

39. Wasfy, T.M., "LEA: advanced environment for multimedia and virtual-reality web-based education and training," DETC2006-99292, $26^{\text {th }}$ Computers and Information in Engineering (CIE) Conference, ASME DETC, Philadelphia, PA, September 2006.

40. Sharable Content Object Reference Model (SCORM), $2^{\text {nd }}$ Edition, 2004. See also URL http:// www.adlnet.org

41. Wasfy, H.M., Wasfy, T.M., Peters, J.M. and Mahfouz, R.M. "No Skill Left Behind: Intelligent Tutoring Systems Enable a New Paradigm in Learning." The $119^{\text {th }}$ Annual American Society for Engineering Education Conference \& Exposition, San Antonio, TX, June 2012.

42. Collins, A. and Halverson, R. "The Second Educational Revolution: Rethinking Education in the Age of Technology." Journal of Computer Assisted Learning, 26, pp. 18-27, 2010.

43. Twigg, C.A. Innovation in Online Learning: Moving Beyond No Significant Difference. The Pew Learning and Technology Program, 2001.

44. Bacon, D.R. and Stewart, K.A. "How fast do students forget what they learn in consumer behavior? A longitudinal study." Journal of Marketing Education, 28(3), pp. 181-192, 2006.

45. Wasfy, H.M, Wasfy, T.M. and Noor, A.K. "An interrogative visualization environment for large-scale engineering simulations.” Advances in Engineering Software, Vol. 35(12), pp. 805-813, 2004.

46. VanLehn, K. "The relative effectiveness of human tutoring, intelligent tutoring systems and other tutoring systems." Educational Psychologist, 46-4, pp. 197-221, 2011.

47. Russell, T. The No Significant Difference Phenomenon: A Comparative Research Annotated Bibliography on Technology for Distance Education, $5^{\text {th }}$ Edition. IDECC, Montgomery, AL, 2001. www.nosignificantdifference.org

48. Bloom, B.S. "The 2 Sigma Problem: The Search for Methods of Group Instruction as Effective as One-on-One Tutoring." Educational Researcher, 13(6), pp. 4-16, 1984.

49. Niemiec, R. and Walberg, H.J. "Comparative effects of computer-assisted instruction: A synthesis of reviews." Journal of Educational Computing Research, 3, pp. 19-37, 1987.

50. Anderson, J.A., Corbett, A.T., Koedinger, K., and Pelletier, R. "Cognitive Tutors: Lessons Learned." The Journal of the Learning Sciences, 4(2), pp. 167-207, 1995.

51. Fernandez, E., Workman-German, J., El-Mounayri, H., and Padalia, C. "Assessment of the Pedagogical Value of an Innovative E-Learning Environment That Uses Virtual Reality", 2008 ASEE IL/IN conference at RoseHulman Institute of Technology, April 3-5, 2008. 
52. Kulik, C.C., and Kulik, J.A. "Effectiveness of computer-based instruction: An updated analysis." Computers in Human Behavior, 7, pp. 75-94, 1991.

53. Browm, A.S. “Automation Vs. Jobs.” Mechanical Engineering. 134-4, pp. 22-27, April 2012.

54. Kolowich, S. "MOOC Host Expands." Inside Higher Ed. Sep 19, 2012. www.insidehighered.com/news/ 2012/09/19/coursera-doubles-university-partnerships

55. www.quotationreference.com/quotefinder.php?strt=1\&subj=Sybil+Marshall\&byax=1\&lr= 